\title{
NOTAS SOBRE DUAS ESPÉCIES DE THELYPTERIS SCHMIDEL (THELYPTERIDACEAE - PTEROPHYTA) DO BRASIL ${ }^{1}$
}

\author{
Alexandre Salino ${ }^{2}$
}

João Semir ${ }^{3}$

Recebido em 25/06/2002. Aceito em 05/05/2003

RESUMO - (Notas sobre duas espécies de Thelypteris Schmidel (Thelypteridaceae - Pterophyta) do Brasil). Durante os estudos taxonômicos das Thelypteridaceae da região Sudeste do Brasil foi constatada a ocorrência de Thelypteris polypodioides (Raddi) C. F. Reed e Thelypteris villosa (Link) C. F. Reed., espécies consideradas raras e pouco conhecidas. A vinculação destas espécies a subgêneros de Thelypteris é controversa na literatura. Sendo assim, neste trabalho são apresentadas chaves de identificação, descrições, ilustrações e dados acerca da distribuição geográfica das espécies, bem como comentários relativos às afinidades taxonômicas destas espécies com os subgêneros de Thelypteris.

Palavras-chave - Thelypteridaceae, taxonomia, Thelypteris, pteridófitas

\begin{abstract}
Notes on two species of Thelypteris Schmidel (Thelypteridaceae - Pterophyta) from Brazil). During the taxonomic study of the Thelypteridaceae from southeastern Brazil was founded Thelypteris polypodioides (Raddi) C. F. Reed and Thelypteris villosa (Link) C. F. Reed, two rare and poorly known species. The taxonomic position of these species is uncertain. This study presents key, descriptions, illustrations, data on geographical distribution, and comments for both species, as well as comments on taxonomic affinity between the two species and Thelypteris subgenera.
\end{abstract}

Key words - Thelypteridaceae, taxonomy, Thelypteris, pteridophytes

1 Parte da tese de Doutorado do primeiro Autor

2 Departamento de Botânica, ICB, Universidade Federal de Minas Gerais, C. Postal 486, CEP 30123-970, Belo Horizonte, MG, Brasil (salino@icb.ufmg.br)

3 Departamento de Botânica, IB, UNICAMP, C. Postal 6109, CEP 13081-970, Campinas, SP, Brasil 


\section{Introdução}

Thelypteridaceae Pic. Serm. é uma das maiores famílias de pteridófitas, com mais de 900 espécies, sendo a maioria de regiões tropicais e subtropicais, com menos de $2 \%$ ocorrendo nas regiões temperadas (Smith 1990). A classificação da família é controversa, havendo autores que reconheceram 32 gêneros (Pichi-Sermolli 1977), 25 gêneros (Holttum 1971), cinco gêneros (Smith 1990) e apenas um gênero (Tryon \& Tryon 1982). Além disso, há o arranjo utilizado por Smith (1992) no tratamento taxonômico da família para a Flora do Peru, no qual o autor reconhece dois gêneros.

De acordo com Smith (1990; 1992; 1995), o gênero Thelypteris é subcosmopolita, com cerca de 875 espécies, das quais aproximadamente 300 ocorrem na região Neotropical. Adotando-se o mesmo arranjo taxonômico proposto por Smith (1992), cinco subgêneros ocorrem no Brasil, a saber: Thelypteris subg. Amauropelta (Kunze) A.R. Sm., Thelypteris subg. Cyclosorus (Link) C.V. Morton, Thelypteris subg. Goniopteris (C. Presl) Duek, Thelypteris subg. Meniscium (Schreber) C.F. Reed e Thelypteris subg. Steiropteris (C. Chr.) Iwats.

No Brasil ocorrem pelo menos 84 espécies do gênero Thelypteris (Salino \& Semir 2002), das quais 65 são encontradas no Sudeste e Sul do país. Dessas 65 espécies, 26 pertencem a Amauropelta, 18 a Goniopteris, sete a Cyclosorus, sete a Meniscium, cinco a Steiropteris e duas espécies pouco conhecidas até o momento e com posição taxonômica incerta.

O objetivo deste trabalho foi caracterizar as duas espécies com posição taxonômica incerta, elaborar chave de identificação das mesmas, descrições e ilustrações, bem como discutir as afinidades taxonômicas com os outros grupos de Thelypteris.

\section{Material e métodos}

O presente estudo foi feito baseado na análise de material coletado pelo primeiro Autor, observações de populações no ambiente natural e em exsicatas provenientes de herbários nacionais e estrangeiros. A abreviação dos nomes dos autores dos táxons está de acordo com Pichi-Sermolli (1996). Para a identificação das espécies foi realizada comparação com material-tipo e com as descrições originais.

$\mathrm{Na}$ confecção das descrições, as medidas dos diâmetros dos pecíolos foram feitas na base, as das larguras das pinas, na região mediana; as dos segmentos, também na região mediana dos mesmos. A distribuição geográfica das espécies foi elaborada com base no material examinado.

\section{Resultados e discussão}

Thelypteris polypodioides (Raddi) C.F. Reed e T. villosa (Link) C.F. Reed foram anteriormente tratadas por Christensen (1913) em Dryopteris subg. Leptogramma J. Sm. [= Thelypteris subg. Stenogramma (Blume) C.F. Reed]. Iwatsuki (1963) comenta que as espécies do subgênero Stenogramma do Novo Mundo apresentam poucas semelhanças (arranjo dos soros e esporângios setosos) com as espécies do Velho Mundo, e diferem destas pela ausência de tricomas e na aparência da folha. Brade (1972) incluiu T. polypodioides e T. villosa no gênero Lastrea Bory. No entanto, Tryon \& Tryon (1982) e Smith (1990) consideraram que as duas espécies não pertencem a Thelypteris subg. Stenogramma e apresentam afinidade incerta. Além disso, Smith (1990) relata que estas duas espécies formam um grupo distinto, que é provavelmente mais relacionado a Thelypteris subg. Goniopteris.

De acordo com Smith (1988), o único representante de Thelypteris subg. Stenogramma no Novo Mundo é Thelypteris pilosa (Martens \& Galeotti) Crawford, que ocorre nos Estados Unidos da América (Alabama), México, 
Honduras e Guatemala. Thelypteris pilosa difere de $T$. polypodioides e T. villosa por apresentar as pinas adnadas e decurrentes com a raque, pelo menos na metade superior da lâmina, além de pinas basais reduzidas e com a base não cuneada.

Chave de identificação das espécies

1. Pecíolo, raque e face abaxial da costa glabros ou leve a moderadamente pubescentes, tricomas curtos (até $0,2 \mathrm{~mm}$ compr.) e unicelulares 1. T. polypodioides

1. Pecíolo, raque e face abaxial da costa com indumento viloso, tricomas longos $(0,7-2 \mathrm{~mm}$ compr.) e pluricelulares; face abaxial da costa às vezes com tricomas unicelulares, sempre maiores que $0,4 \mathrm{~mm}$ 2. T. villosa

1. Thelypteris polypodioides (Raddi) C. F. Reed, Phytologia 17(4): 305. 1968.

Ceterach polypodioides Raddi, Opusc. Sci. Bologn. 3:284. 1819.

Dryopteris polypodioides (Raddi) C. Chr., Ind.: 285. 1905.

Tipo: Brasil. Rio de Janeiro, Raddi s.n. (Holótipo, FI, não visto).

Fig. 1 A-D.

Caule curto a médio reptante, geralmente glabro ou com pouquíssimas escamas estreito lanceoladas, castanho-claras a castanho-avermelhadas, geralmente glabras, raramente com tricomas esparsos. Folhas 0,43-1,22m compr., monomorfas. Pecíolo 11-60cm compr. $\times$ 3-5,2mm diâm., na base com escamas iguais às do caule; glabrescente a moderadamente pubescente. Lâmina $15-65 \mathrm{~cm}$ compr., herbácea a cartácea, 1-pinada-pinatífida, com contorno lanceolado a oval, com ápice subabruptamente reduzido e pinatífido, base não reduzida. Raque moderadamente curto pubescente. Gemas ausentes. Aeróforos ausentes. Pinas (4) 6-13 pares, $8-21 \mathrm{~cm}$ compr. $\times 1,5-3 \mathrm{~cm}$ larg., ascendentes, elípticas, as distais sésseis e as medianas e proximais pecioluladas (até $5 \mathrm{~mm}$ compr.), com ápice acuminado, base truncada nas distais, oblíqua a cuneada nas medianas e longo cuneada nas proximais; incisão de $2 / 3$ da distância entre a costa e a margem da pina; escamas costais ausentes; face adaxial pubescente apenas na costa; face abaxial esparsamente pubescente na costa. Segmentos 4-8mm larg., falciformes, com ápice arredondado ou agudo, margens inteiras, planas. Nervuras 8-13 pares por segmento, simples, às vezes bifurcadas, as basais de segmentos adjacentes unindo-se ao enseio e geralmente mais uma nervura basiscópica unindo-se ao enseio; a nervura basal basiscópica parte da junção da costa com a cóstula ou base da cóstula, a nervura acroscópica parte da costa. Indumento de tricomas setiformes, unicelulares, 0,05-0,2mm compr., presente nas escamas, no pecíolo, na raque, em ambas as faces da costa, nas margens dos segmentos e na face abaxial das cóstulas e nervuras; tricomas glandulares ausentes. Soros medianos a supramedianos, elípticos a lineares, arqueados, às vezes confluentes na maturidade; indúsio ausente; esporângios com 1-3 tricomas setiformes na cápsula, raramente pedicelo com um tricoma.

Material examinado: BRASIL. Bahia: Itacaré, 8/II/1979, Mori et al. 11502 (HEPH, NY). Espírito Santo: Domingos Martins, 14/III/1989, Behar 246 \& Viégas (SJRP, UFES). Minas Gerais: Almenara, Fazenda Limoeiro, Mata da Mamoneira, 23/II/2003, Salino 8294 (BHCB); Caratinga, Estação Biológica de Caratinga, 11/XII/1995, Salino 2375 (BHCB, UEC). Rio de Janeiro: Itatiaia, I/1938, Brade 16047 (RB); Parati, próximo ao Condomínio Laranjeiras, 15/XI/1993, Salino $1910 b$ (BHCB); idem, Corcovado, 8/IX/1874, Mosén 2656 (C, S); idem, Tijuca, 27/VI/1906, Usteri 17 (SP); idem, entre Jardim Botânico e Alto da Boa Vista, 27/XI/1928, Smith 1366 (US); idem, Estrada entre Sylvestre e Paineiras, 4/IV/1929, Smith 2248 (GH, US); Serra da Estrela, s.d., Gaudichaud s.n. (UC). São Paulo: Iguape, Juquiá, VI/1921, Brade 8511 (UC); 
idem, Morro das Pedras (Morro Secco), VII/1921, Brade s.n. (US); Peruíbe, Praia do Guaraú, 18/X/1998, Salino 4398 \& Morais (BHCB); Piaçaquera, V/1913, Brade 6274 (NY, UC, S, $\mathrm{SP}$ ); idem, V/1913, Tamandaré 630 (RB); Ubatuba, Maranduba, 1/VI/1996, Dittrich 268 (BHCB); Serra do Mar, 1906, Wacket s.n. (RB, S, US); T. Toquera, 6/X/1912, Dusén s.n. (S).

Thelypteris polypodioides é muito semelhante a $T$. villosa, porém esta espécie possui o pecíolo, raque e face abaxial da costa com indumento viloso, com tricomas longos (0,7-2mm compr.), simples e pluricelulares. Já T. polypodioides possui tricomas unicelulares e curtos, com até $0,2 \mathrm{~mm}$ compr. Thelypteris villosa também pode apresentar tricomas unicelulares na face abaxial da costa, porém são sempre maiores que $0,4 \mathrm{~mm}$. No aspecto geral e na forma das pinas proximais, Thelypteris polypodioides assemelha-se bastante a várias espécies de Goniopteris, principalmente Thelypteris cuneata (C. Chr.) C.F. Reed, porém esta espécie possui tricomas ramificados e/ou estrelados, pelo menos nas escamas do caule, no pecíolo, na raque e face abaxial da costa; os soros são arredondados e os esporângios são glabros. A ocorrência de tricomas simples na cápsula dos esporângios é rara nas espécies de Thelypteris subg. Goniopteris, tendo sido registrada apenas em T. tetragona (Sw.) Small. Além disso, exemplares estéreis de T. polypodioides podem ser confundidos com Ctenitis aspidioides (C. Presl) Copel. (Tectariaceae), mas que podem ser separadas pela presença de tricomas articulados e com ápice obtuso na última espécie. Eventualmente, T. polypodioides pode ser confundido com algumas espécies de Diplazium (Woodsiaceae) que possuem lâmina 1-pinada-pinatífida, isto por apresentarem soros lineares sobre as nervuras. No entanto, as espécies de Diplazium possuem soros indusiados.

Thelypteris polypodioides ocorre apenas no Brasil, nos Estados da Bahia, Espírito Santo, Minas Gerais, Rio de Janeiro e São Paulo. Até o momento, T. polypodioides era pouco conhecida, com citações apenas para os Estados de São Paulo e Rio de Janeiro (Brade 1972). Sendo assim, a espécie está aqui sendo referida pela primeira vez para a Bahia, Espírito Santo e Minas Gerais. Thelypteris polypodioides ocorre exclusivamente em áreas de Floresta Atlântica, preferencialmente no interior de florestas úmidas de encosta, desde o nível do mar até ca. $1.300 \mathrm{~m}$ de altitude.

2. Thelypteris villosa (Link) C.F. Reed, Phytologia 17(4): 323. 1968.

Gymnogramma villosa Link, Hort. Berol., 2: 51. 1833.

Dryopteris dasyphylla C. Chr., Ind. Fil.: 260. 1905.

Lastrea dasyphylla (C. Chr.) Copel. Gen. Fil.: 138. 1947.

Tipo: Brasil, baseado em plantas cultivadas no Hort. Berol. (Berlim) (Holótipo, B!).

Fig. 1 E-I.

Caule curto a médio reptante, geralmente escamoso com escamas estreito lanceoladas, castanho escuras a marrons, geralmente glabras. Folhas 54,5-196,6cm compr., monomorfas. Pecíolo 36,0-48,5cm compr. $\times 2,98-4,0 \mathrm{~mm}$ diâm., na base com escamas iguais às do caule; glabrescente a moderadamente pubescente. Lâmina 18,5-48,5cm compr., cartácea, 1-pinadapinatífida, com contorno lanceolado, com ápice subabruptamente reduzido, pinatífido, base não reduzida. Raque geralmente com indumento viloso. Gemas ausentes. Aeróforos ausentes. Pinas (2) 8-13 pares, $11-18 \mathrm{~cm}$ compr. $\times 2,3-3,0 \mathrm{~cm}$ larg., levemente ascendentes, elípticas, as distais sésseis e as medianas e proximais subsésseis a curto-pecioluladas (até 2,0mm compr.), com ápice acuminado, base truncada nas distais, oblíqua a cuneada nas medianas e longo e subabruptamente cuneada nas proximais; incisão de 2/3 ou maior do que a distância entre a costa e a margem da pina; escamas costais ausentes; face adaxial pubescente na costa, cóstula e nervuras; face abaxial pubescente na 


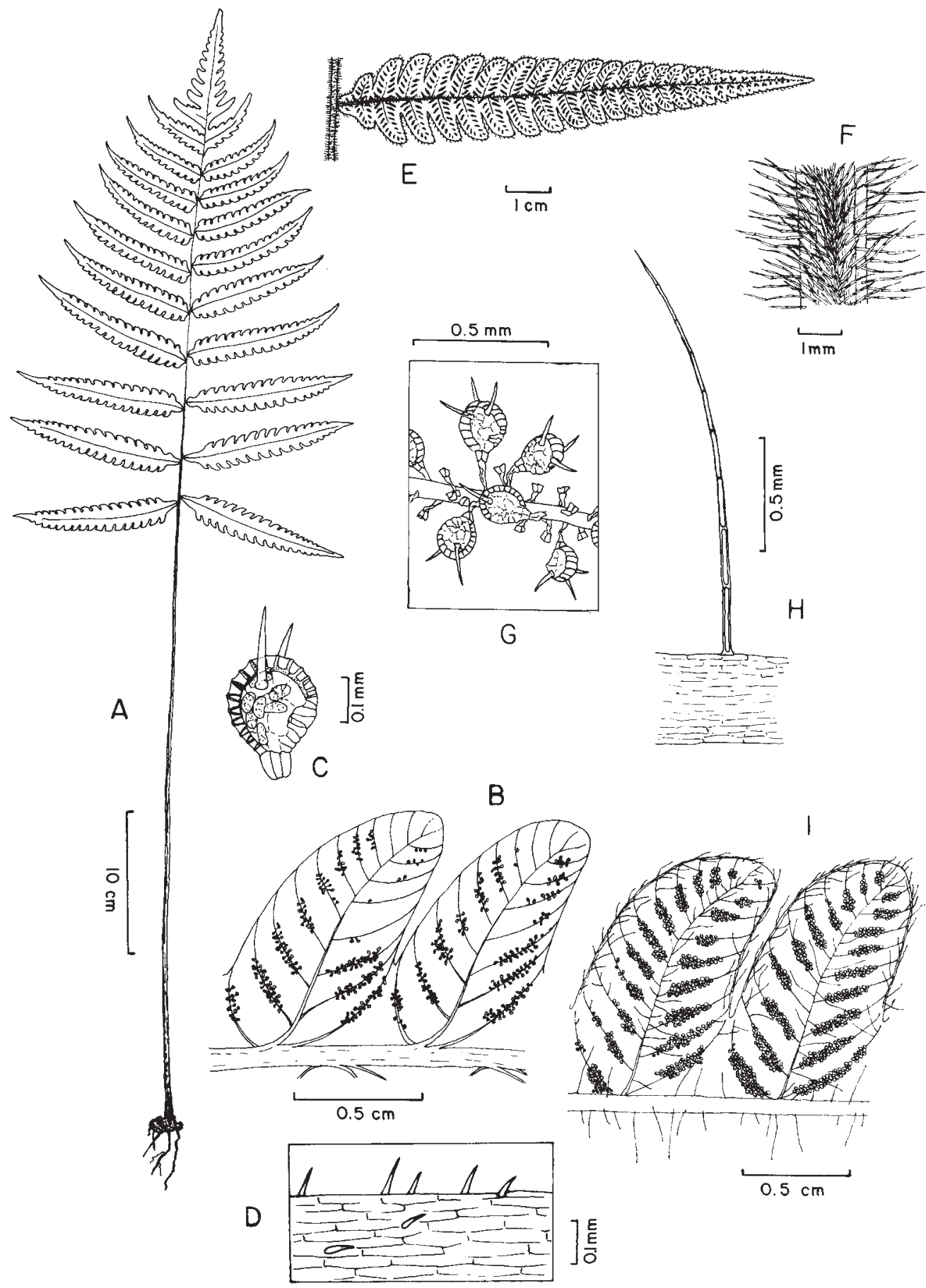

Figura 1. A-D. Thelypteris polypodioides (Brade 6274). A. Hábito. B. Detalhe da face abaxial dos segmentos e da costa, mostrando as nervuras e os soros alongados. C. Detalhe de um esporângio setoso. D. Detalhe da face abaxial da costa, mostrando os tricomas unicelulares. E-I. Thelypteris villosa (Sucre 2172). E. Pina mediana. F. Detalhe da raque, mostrando o aspecto viloso. G. Detalhe dos esporângios com tricomas setiformes na cápsula. H. Detalhe de um tricoma longo e pluricelular. I. Detalhe da face abaxial dos segmentos e da costa, mostrando as nervuras, os soros alongados e os tricomas. 
costa, costula e nervuras. Segmentos 5,7-7,1 mm larg., arqueados, com ápice geralmente arredondado, margens inteiras e planas. Nervuras 8-11 pares por segmento, simples, as basais de segmentos adjacentes unindo-se ao enseio ou próximo a este; a nervura basal acroscópica parte da costa e a nervura basal basiscópica parte da junção da costa com a cóstula. Indumento de tricomas setiformes, pluricelulares e longos $(0,7-2,0 \mathrm{~mm}$ compr.) presente no pecíolo, raque, ambas as faces da costa, cóstula, nervuras e margens dos segmentos. Soros medianos a inframedianos, elípticos a lineares, às vezes oblongos, arqueados, às vezes confluentes na maturidade; indúsio ausente; esporângios geralmente com 2 a 3 tricomas setiformes na cápsula, pedicelo geralmente glabro.

Material examinado: BRASIL. Rio de Janeiro: Rio de Janeiro, Parque Lage, Mata Secundária, 25/I/1968, Sucre 2172 (RB); Serra dos Órgãos, Frade, 1923, Spannagel 577 (NY).

Thelypteris villosa é fortemente relacionada a $T$. polypodioides, porém esta espécie possui a folha glabra ou muito esparsamente pubescente, com tricomas unicelulares e curtos, com até $0,2 \mathrm{~mm}$ compr.

Thelypteris villosa é espécie rara e endêmica da Floresta Atlântica do Estado do Rio de Janeiro, onde cresce sobre rochas, geralmente próximo a cursos d'água, no interior de Floresta Atlântica de encosta, de próximo ao nível do mar até cerca de $1.300 \mathrm{~m}$ de altitude.

Thelypteris polypodioides e T. villosa aparentemente formam grupo morfologicamente diferente dos outros subgêneros de Thelypteris, que pode ser caracterizado pelo caule reptante; lâmina 1-pinada pinatífida, com ápice sub-abruptamente reduzido e base não reduzida, pinas proximais com base cuneada, gemas e aeróforos ausentes, nervuras basais de segmentos adjacentes unindo-se no enseio ou a margem pouco acima, soros alongados, geralmente lineares, às vezes oblongos, sem indúsio, esporângios setosos, com 2-5 tricomas setiformes na cápsula.

Esporângios setosos aparecem em poucas espécies do gênero Thelypteris, distribuídas em vários subgêneros que ocorrem no Brasil, como Thelypteris subg. Amauropelta, Thelypteris subg. Goniopteris, Thelypteris subg. Meniscium e Thelypteris subg. Steiropteris.

Para estabelecer uma posição taxonômica mais adequada para Thelypteris polypodioides e Thelypteris villosa serão necessárias informações acerca da morfologia dos esporos e o número de cromossomos, bem como de um estudo comparativo (análise filogenética) da família Thelypteridaceae, incluíndo representantes do Velho Mundo.

\section{Referências bibliográficas}

Brade, A. C. 1972. O gênero Dryopteris (Pteridophyta) no Brasil e sua divisão taxonômica. Bradea 1(22): 191-261.

Christensen, C. 1913. A monograph of the genus Dryopteris, Part I, The tropical American pinnatifid-bipinnatifid species. Kongelige Danske Videnskabernes Selskabs Skrifter Naturdidenskabeliger og Mathematisk Afdeling 10: 55-282.

Holttum, R. E. 1971. Studies in the family Thelypteridaceae III. A new system of genera in the Old World. Blumea 19: 17-52.

Iwatsuki, K. 1963. Taxonomic studies of Pteridophyta VII. A revision of the genus Stenogramma Emend. Acta Phytotaxonomica Geobotanica 19: 112-126.

Pichi Sermolli, R. E. G. 1977. Tentamen pteridophytorum genera in taxonomicum ordinem redigendi. Webbia 31: 313-512.

Pichi Sermolli, R. E. G. 1996. Authors of scientific names in Pteridophyta. Royal Botanic Gardens, Kew.

Salino, A. \& Semir, J. 2002. Thelypteridaceae (Polypodiophyta) do Estado de São Paulo: Macrothelypteris e Thelypteris subgêneros Cyclosorus e Steiropteris. Lundiana 3: 9-27.

Smith, A. R. 1988. Thelypteris. In: J. T. Mickel \& J. M. Beitel (eds.). Pteridophyte Flora of Oaxaca, Mexico. Memoirs of the New York Botanical Garden 46: 361-388. 
Smith, A. R. 1990. Thelypteridaceae. Pp. 263-272. In: K. U. Kramer \& P. S. Green (eds.). The families and genera of vascular plants. Vol. I. Pteridophytes and Gymnosperms. Springer Verlag, New York.

Smith, A. R. 1992. Thelypteridaceae. In: R. M. Tryon \& R. G. Stolze (eds.). Pteridophyta of Peru. Part III. Fieldiana Botany New Series 29: 1-80.
Smith, A. R. 1995. Thelypteridaceae. Pp. 164-195. In: G. Davidse (ed.). Flora Mesoamericana. Psilotaceae a Salviniaceae. Universidad Nacional Autónoma de México, México, D.F.

Tryon, R. M. \& Tryon, A. F. 1982. Fern and allied plants, with special reference to tropical America. Springer Verlag, New York. 